\title{
Autonomous Regulation Mode Moderates the Effect of Actual Physical Activity on Affective States: An Ambulant Assessment Approach to the Role of Self-Determination
}

\author{
Martina Kanning, ${ }^{1}$ Ulrich Ebner-Priemer, ${ }^{2}$ and Ralf Brand ${ }^{3}$ \\ ${ }^{1}$ University of Stuttgart; ${ }^{2}$ Karlsruhe Institute of Technology; \\ ${ }^{3}$ Potsdam University
}

\begin{abstract}
Studies have shown that physical activity influences affective states. However, studies have seldom depicted these associations in ongoing real-life situations, and there is no investigation showing that motivational states (i.e., more or less autonomously regulated) would moderate these effects in situ. To investigate the interaction of autonomous regulation and actual physical activity (aPA) with affective states, we use an ambulatory assessment approach. The participants were 44 university students (mean age: $26.2 \pm 3.2$ years). We assessed aPA through 24-hr accelerometry and affective states and autonomous regulation via electronic diaries. Palmtop devices prompted subjects every 45 min during a 14-hr daytime period. We performed hierarchical multilevel analyses. Both aPA and autonomous regulation significantly influenced affective states. The interaction was significant for two affects. The higher the volume of aPA and thereby the more autonomously regulated the preceding bout of aPA was, the more our participants felt energized $(r=.16)$ but agitated $(r=-.18)$.
\end{abstract}

Keywords: ecological momentary assessment, feelings, activities of daily living

There is strong evidence that acute bouts of exercise (Reed \& Ones, 2006) and regular exercise (Puetz, O'Connor, \& Dishman, 2006) each have the potential to increase subjective well-being. Recent studies even show such effects for physical activities during every day life (Kanning \& Schlicht, 2010). Physical activities during every day life include all possible activities in which people are ambulating, walking, running, or doing some kind of exercise, for instance. Those activities are named here as actual physical activities (aPA).

Martina Kanning is with the Department of Sport and Exercise Science, University of Stuttgart, Stuttgart, Germany. Ulrich Ebner-Priemer is with the Department of Sport and Sport Science and House of Competence, Karlsruhe Institute of Technology, Karlsruhe, Germany. Ralf Brand is with the Department of Sport and Exercise Psychology, Potsdam University, Potsdam, Germany. 
Self-determination theory (SDT; e.g., Ryan \& Deci, 2000) has been used to explain the link between behavior and subjective well-being, and may also moderate the effect of aPA on affective states. According to SDT, a person's behavior can be regulated more or less autonomously. The more a behavior is intrinsically motivated (i.e., "self-determined") the more this behavior is able to satisfy the individual's psychological need for autonomy, resulting in increased well-being (Ryan \& Deci, 2000). Located on a relative autonomy continuum from controlling to autonomous regulation, SDT indicates an external regulation mode (lowest degree of self-determination) if the person seeks to satisfy an external demand or reward (e.g., exercising only because of one's doctor's recommendation). Introjected regulation is presumed if an activity is done to pursue contingent self-worth, while avoiding feelings of shame is still a persistent factor. Identified regulation means that a behavior corresponds to personally held values. Intrinsic regulation then would refer to physically active behaviors, which are done for their own sake and pleasure with no discernible reinforcement or reward necessary (fully integrated in one's value system; highest degree of self-determination).

Reis, Sheldon, Gable, Roscoe, and Ryan (2000) investigated Sheldon's and Elliot's (1999) hypothesis that autonomously regulated activities are connected with positive changes in well-being. Every evening for 14 days, participants had to retrospectively rate their affective states and how autonomous they felt in regulating the most relevant physical activities of that day. Using multilevel modeling to inspect within-person effects, these authors showed that positive changes in well-being correspond with autonomously regulated activities (see also Smith, Ntoumanis, Duda, \& Vansteenkiste, 2011).

Duncan, Hall, Wilson and Jenny (2010) have shown that self-reported behavioral indices of exercise (frequency, intensity, and duration of exercise sessions) are associated with more autonomous regulation modes. This finding has been replicated by Taylor, Ntoumanis, Standage, and Spray (2010) using multilevel modeling techniques to inspect within-person effects (see also Sebire, Standage, \& Vansteenkiste, 2011; Wilson, Blanchard, Nehl \& Baker, 2006; Wilson, Rodgers, Fraser, \& Murray, 2004).

But, to our best knowledge, no former study has so far analyzed whether this interaction of aPA and autonomous regulation on affective states represents an acute effect that occurs instantly with a rather direct link to the precipitating behavior, or an effect that is rather deliberately processed in the hindsight. The latter possibility might be seen as a methodological impairment of existing studies. There, aPA is often assessed through retrospective self-reports. Systematic reviews, however, have shown that the correlations between subjective (e.g., questionnaire, diary) and objective (mostly accelerometry) measures of aPA are only low to moderate (Prince et al., 2008). Similar criticism has been raised regarding the retrospective assessment of affective states. Yet the recall of affective states is often based on biased storage and recollection of memories (Ebner-Priemer \& Trull, 2009). The ambulatory assessment methodology (e,g., Fahrenberg, Myrtek, Pawlik, \& Perrez, 2007) has the potential to resolve these problems by utilizing computerized devices to investigate daily life self-reports, physiology, or behavior in (nearly) real time and (almost) fully integrated in the natural flow of behaviors. To increase (ecological) validity and reliability, we combined acceleration sensors to objectively 
measure routine aPA with digital diaries that allowed us to track affective states across real-life situations.

Expanding the existing state of research, we tested the hypotheses that aPA in daily life (Main Effect A) and autonomous regulation (Main Effect B) differentially affect multidimensional affective states as an acute effect, which is embedded in the flow of ongoing behaviors. Above all, our interest is with the interaction between these two variables $(\mathrm{A} \times \mathrm{B})$. We hypothesize that the higher the volume of aPA and thereby the more autonomously regulated the preceding bout of aPA was, the greater its acute effects on affective states will be.

\section{Methods}

\section{Participants}

A convenience sample, recruited at a German university, was used for testing these assumptions. Participants were 23 men and 21 women (mean age: $26.2 \pm$ 3.2 years). All participants were studying sport and exercise science in their fourth semester. They all were Caucasian and nearly all of them (89\%) were unmarried. Before recording the data, participants were informed about the study's aims and had to declare informed consent. Institutional ethical approval was obtained before the conducting of the study. Participants received no financial compensation for their efforts.

\section{Ambulatory Assessment Procedure}

Actual physical activity was measured continuously using a 3-way accelerometer (Varioport-e; Becker Meditech, Germany) attached for $24 \mathrm{hr}$ at the participant's hip. Ratings for affective states and regulation mode were assessed with digital palmtop devices (Palm, Tungsten E2; software: Izybuilder, http://izybuilder.com/ home), and subjects were prompted approximately every 45 min during a defined 14-hr daytime period (between 8:00 a.m. and 10:00 p.m.). This sampling rate led to an average of 19 recordings per participant $(N=44)$, resulting in a total of 830 data points.

Affective States. A six-item short scale of the Multidimensional Mood Questionnaire (MDMQ; Steyer, Schwenkmezger, Notz, \& Eid, 1997) was applied, which has been explicitly developed and evaluated for ambulatory assessment (Wilhelm \& Schoebi, 2007). Participants indicated on a six-point scale the extent to which they were experiencing different qualities of momentary affective states. The MDMQ short scale measures the basic affective states valence (well-unwell), calmness (relaxed-agitated), and energetic arousal (energized-tired) with two bipolar items for each subscale. Subscale scores range from 0 (low value) to 10 (high value). Homogeneity was assessed for the between-person level and for the within-person level. In our data set, the level-specific reliability coefficient for the between-person level was not less than .90 (level-specific reliability). For the within-person level, the value was at least .70, indicating satisfying internal scale consistencies. 
Relative Autonomy Index (RAI). The RAI has been proposed by Sheldon and Elliot (1999), with the respective scale reaching a high level of internal consistency (Cronbach's $\alpha=.80$ ). Participants were asked to rate items mirroring possible regulation modes of their ongoing activities. After the prompt, "I was engaged in this activity over the last 10 minutes because ...." participants responded to all of the four items, "I just felt like doing it" (intrinsic regulation), "I believe these activities were meaningful and important" (identified regulation), "I didn't want to be blamed by someone" (introjected regulation), and "I wanted to be recognized by others for doing that" (external regulation) on 6-point scales ranging from 0 (not at all for this reason) to 5 (solely for this reason). According to recent recommendations on the scoring of this scale (Reis et al., 2000), the RAI was calculated by adding intrinsic and identified scores and subtracting the added introjected and external scores.

Actual Physical Activity (aPA). The 3-dimensional acceleration signal was combined into one global index of aPA by the interactive software package Freiburg Monitoring System, according to a published procedure (Myrtek, 2004). The technical details are as follows. Acceleration, measured in milli- $g$, was separated offline into AC and DC components by a FIR digital filter with a cut-off frequency at $0.5 \mathrm{~Hz}$. Rectified $\mathrm{AC}$ values were averaged across data points for each minute in a $24-\mathrm{hr}$ period. The $10 \mathrm{~min}$ of aPA preceding the electronic diary prompt were averaged over the previous $10 \mathrm{~min}$, to analyze lagged within-subject relations of aPA, autonomous regulation, and corresponding affective states.

\section{Analyses}

As our assessment resulted in hierarchically structured data in which repeated measurements of PA, RAI, and affective states (Level 1) are nested within persons (Level 2), we applied multilevel analyses using the statistical program HLM 6.0 (Raudenbush, Bryk, \& Congdon, 2004). Multilevel analyses were conducted separately for each affect subscale: valence, energetic arousal, and calmness. Unconditional models of the three subscales revealed that the average levels of valence, energetic arousal, and calmness were $M=7.1,5.9$, and 6.9, respectively, representing medium to high ranges of daily affective states. The intraclass coefficient was $\rho_{I}=.33$ for valence, $\rho_{I}=.17$ for energetic arousal, and $\rho_{I}=.28$ for calmness, indicating that $67 \%, 83 \%$, and $72 \%$ of the affect subscales' variance was caused by intraindividual variation. This supports analyzing time-variant predictors in real-life situations. In the following step, the predictor variables aPA and RAI and the interaction term aPA $\times$ RAI were entered consecutively into the model.

$$
\begin{aligned}
\text { Level 1: } Y_{t i}=\beta_{0 i}+ & \beta_{1 i}(\mathrm{aPA})_{t i}+\beta_{2 \mathrm{i}}(\mathrm{RAI})_{t i} \beta_{3 i}(\mathrm{aPA} \times \mathrm{RAI})_{t i}+r_{t i} \\
& \text { Level 2: } \beta_{0 i}=\gamma_{00}+\mu_{0 i} \\
& \text { Level 2: } \beta_{1 i}=\gamma_{10}+\mu_{1 i} \\
& \text { Level 2: } \beta_{2 i}=\gamma_{20}+\mu_{2 i} \\
& \text { Level 2: } \beta_{3 i}=\gamma_{30}+\mu_{3 i}
\end{aligned}
$$


Level 1 represents participants' response (subscript ${ }_{i}$ ) reported on one of the basic affect subscales $\left(Y_{t i}\right)$ in any given diary entry (subscript ${ }_{t}$ ). The term $Y_{t i}$ is defined as the average intercept of the correspondent affect subscale across all participants $\left(\beta_{0 i}\right)$, the three Level-1 predictors aPA $\left(\beta_{1 i} \mathrm{aPA}_{t i}\right), \mathrm{RAI}\left(\beta_{2 i} \mathrm{RAI}_{t i}\right)$, and the interaction between aPA and RAI $\left(\beta_{3 i} \mathrm{aPA} \times \mathrm{RAI}_{t i}\right)$. These predictors are group mean centered, with group referring to a person (Level 2). Therefore, the slopes refer to increases or decreases beyond an individual's normal level of PA, RAI, and the interaction. Intercepts and slopes are conceived as varying randomly. The random effect for the Level-1 model is given by $r_{t i}$. It is assumed to be normally distributed, with a mean of " 0 " and variance of $\sigma^{2}$. Level 2 is unconditional and includes the fixed effects, $\gamma$, as the average intercepts and slopes across all persons and the random effects, $\mu$. These random effects are assumed to be multivariate and normally distributed, both with expected values of 0 .

The alpha level of the tests was set to $p<.05$. Restricted maximum likelihood estimations were used for the multilevel analyses. According to the nested structure of the model, effect size estimations were calculated with effective degrees of freedom. Formula 6 was used to calculate the $N_{\text {effective }}$ of the models (Snijders \& Bosker, 2011).

$$
N_{\text {effective }}=N n /\left[1+(n-1) \times \rho_{\mathrm{I}}\right)
$$

where $\mathrm{N} n$ stands for the number of measurements points, $n$ stands for the average measurement points per person, and $\rho_{\mathrm{I}}$ represents the intraclass coefficient of the affect subscale of interest. Effective degrees of freedom are analyzed with $N_{\text {effective }}$ minus the number of predictors. We calculate effect size $r$ using $t$ values and effective degrees of freedom.

\section{Results}

For the analyses of within-person effects, 830 data points of aPA and RAI with corresponding affective states were available. Across all 10-min episodes, participants were physically active with $77.3 \mathrm{milli}-\mathrm{g} / \mathrm{min}$, on average $(S D=94.3)$, with a range from 0.8 to 994.4 milli-g/min. For comparison, jogging episodes reveal about $1000 \mathrm{milli}-\mathrm{g} / \mathrm{min}$, walking episodes about $350 \mathrm{milli}-\mathrm{g} / \mathrm{min}$, and pure sitting episodes approximately $10 \mathrm{milli}-\mathrm{g} / \mathrm{min}$. The distribution of PA, RAI, and the three affect subscales allow for multilevel analyses.

Random error terms of three slopes are not significant in all models. They have to be fixed because the random and the fixed variability of the slopes cannot be reliably separated. For valence, aPA and the interaction were fixed and for calmness the interaction was fixed (Table 1).

The within-person effects of aPA and RAI on affective states are separately shown for each of the three basic affects in Table 2. Valence was significantly predicted by PA, as well as by RAI with small-to-moderate effect sizes $(r=.18$ for PA; $r=.35$ for RAI). The more our subjects were physically active during the preceding $10 \mathrm{~min}$, the more they felt well and satisfied. In addition, the more they regulated their activities autonomously, the more they felt well and satisfied. However, data analysis did not reveal a significant effect for the hypothesized interaction 
Table 1 Variance Components of Between-Person Effects for Intercepts of the Outcome Variables (Valence, Energetic Arousal, Calmness) and Slopes of Actual Physical Activity (aPA), Relative Autonomy Index (RAI), and the Interaction of aPA and RAI

\begin{tabular}{|c|c|c|c|c|}
\hline $\begin{array}{l}\text { Variance Components Between } \\
\text { Persons }\end{array}$ & $\begin{array}{l}\text { Variance } \\
\text { Estimate }\end{array}$ & SE & $\chi^{2}(d f)$ & $p$-value \\
\hline \multicolumn{5}{|l|}{ Model 1: Valence } \\
\hline Intercept $\left(\mu_{0 i}\right)$ & 1.48 & 1.22 & $490.21(43)$ & $<.001$ \\
\hline aPA slope $\left(\mu_{1 i}\right)$ & fixed & & & \\
\hline RAI slope $\left(\mu_{2 i}\right)$ & 0.02 & 0.14 & $102.61(43)$ & $<.001$ \\
\hline Interaction slope $\left(\mu_{3 i}\right)$ & fixed & & & \\
\hline Level-1 $\left(r_{t i}\right)$ & 2.69 & 1.64 & & \\
\hline \multicolumn{5}{|l|}{ Model 2: Energetic Arousal } \\
\hline Intercept $\left(\mu_{0 i}\right)$ & 1.09 & 1.05 & $220.5(43)$ & $<.001$ \\
\hline aPA slope $\left(\mu_{1 i}\right)$ & 0.00003 & 0.006 & $90.8(43)$ & $<.001$ \\
\hline RAI slope $\left(\mu_{2 i}\right)$ & 0.01 & 0.11 & $66.15(43)$ & .01 \\
\hline Interaction slope $\left(\mu_{3 i}\right)$ & 0.00001 & 0.002 & $85.6(43)$ & $<.001$ \\
\hline Level-1 $\left(r_{t i}\right)$ & 4.86 & 2.20 & & \\
\hline \multicolumn{5}{|l|}{ Model 3: Calmness } \\
\hline Intercept $\left(\mu_{0 i}\right)$ & 1.21 & 1.10 & $418.1(43)$ & $<.001$ \\
\hline aPA slope $\left(\mu_{1 i}\right)$ & 0.00002 & 0.004 & $75.7(43)$ & .002 \\
\hline RAI slope $\left(\mu_{2 i}\right)$ & 0.01 & 0.10 & $70.4(43)$ & .005 \\
\hline Interaction slope $\left(\mu_{3 i}\right)$ & fixed & & & \\
\hline Level-1 $\left(r_{t i}\right)$ & 1.60 & 2.57 & & \\
\hline
\end{tabular}

aPA $\times$ RAI, $p=.82$. Energetic arousal was positively affected by aPA $(r=.38)$ but not by RAI $(p=.06)$. The interaction effect is significant but small $(r=.16)$, still illustrating that the higher the volume of aPA and thereby the more autonomously regulated the preceding bout of aPA was, the more our participants felt energized and awake. Actual PA had a significant negative effect on calmness $(r=-.21)$. The more the subjects were physically active, the more they felt agitated and tense. On the other hand, calmness was significantly and positively related with RAI ( $r=$ .48 ), which means that the more a behavior was autonomously regulated, the more the subjects felt calm and relaxed. The interaction aPA $\times$ RAI exerted a significant and negative effect on calmness $(r=-.18)$, indicating that the higher the volume of aPA and thereby the more autonomously regulated the preceding bout of aPA was, the more the sample felt agitated and tense. 
Table 2 Within-Subject Fixed Effects for Intercepts of the Outcome Variables (Valence, Energetic Arousal, Calmness) and Slopes of Actual Physical Activity (aPA), Relative Autonomy Index (RAI), and the Interaction of aPA and RAI

\begin{tabular}{lcccc}
\hline Within-Subject Fixed Effects & Coefficient & SE & $\boldsymbol{t}$ value $(\boldsymbol{d} \boldsymbol{f})$ & $\boldsymbol{p}$-value \\
\hline Model 1: Valence & & & & \\
Intercept $\left(\beta_{0 i}\right)$ & 7.17 & 0.19 & $37.27(43)$ & $<.001$ \\
aPA slope $\left(\beta_{1 i}\right)$ & 0.001 & 0.0007 & $2.02(817)$ & .04 \\
RAI slope $\left(\beta_{2 i}\right)$ & 0.12 & 0.03 & $4.09(43)$ & $<.001$ \\
Interaction slope $\left(\beta_{3 i}\right)$ & 0.00005 & 0.0002 & $0.23(817)$ & .82 \\
Model 2: Energetic Arousal & & & & \\
Intercept $\left(\beta_{0 i}\right)$ & 5.94 & 0.18 & $34.84(43)$ & $<.001$ \\
aPA slope $\left(\beta_{1 i}\right)$ & 0.01 & 0.001 & $5.91(43)$ & $<.001$ \\
RAI slope $\left(\beta_{2 i}\right)$ & -0.06 & 0.03 & $-1.91(43)$ & .06 \\
Interaction slope $\left(\beta_{3 i}\right)$ & 0.001 & 0.0005 & $2.31(43)$ & .03 \\
Model 3: Calmness & & & & \\
Intercept $\left(\beta_{0 i}\right)$ & 6.89 & 0.18 & $39.35(43)$ & $<.001$ \\
aPA slope $\left(\beta_{1 i}\right)$ & -0.002 & 0.001 & $-2.50(43)$ & .02 \\
RAI slope $\left(\beta_{2 i}\right)$ & 0.16 & 0.02 & $6.38(43)$ & $<.001$ \\
Interaction slope $\left(\beta_{3 i}\right)$ & -0.0005 & 0.0002 & $-2.51(817)$ & .01 \\
\hline
\end{tabular}

\section{Discussion}

Our findings support the hypothesis that aPA and autonomous regulation modes, as well as their interaction, have an impact on affective states in the shape of an acute effect, which is embedded in the ongoing flow of behaviors. Regarding the effect of aPA on affective states, we show that the more our subjects were physically active, the more they felt well (valence), awake (energetic arousal), but agitated (calmness [-]).

Earlier studies have already demonstrated that even unstructured lifestyle physical activities of low-to-moderate intensities can positively affect a person's affective state (Kanning \& Schlicht, 2010). Similarly to our study, these authors have assessed data during real-life situations. But they had asked their subjects to self-select and then describe this selected aPA episode together with the concurrent affective state. Thus, this study faces two problems: neither was aPA assessed objectively (we did this via accelerometers), nor were the authors able to control (we did this with an electronic diary) when participants gave their answers on affective states (i.e., whether participants answered exactly every 45 min throughout the day or whether they answered to all questions in the evening, for instance). This may explain that, in contrast to their study, we have found negative correlations with 
calmness (i.e., our participants felt more agitated and tense after episodes of aPA). We propose that these differing results are mainly due to the fact that we did not let our subjects self-decide on which aPA episodes they wanted to report. We had prompted them to do so unexpectedly. This gave us the opportunity to question participants even in the course of ongoing physical activities. Maybe the relaxing effects (calmness [+]) of aPA, as reported in the study of Kanning and Schlicht (2010), appear only after a time delay when the direct experience of having been physically active has been reevaluated. Future studies should assess the association of aPA and sense of calm in more detail by using different time lags. An alternative explanation may be that participants simply felt disturbed by the measurement prompt. We cannot address this hypothesis with our data, and maybe further research has to be conducted to clarify this.

Regarding the effects of regulation modes on affective states, we could show that the more autonomously an activity is regulated, the more our subjects felt well (valence) and calm (calmness). These results are in line with the assumption of the self-determination theory (Ryan \& Deci, 2000). Our study transcends the existing research (e.g., Reis et al., 2000; Sheldon \& Elliot, 1999, Smith et al., 2011), as we have demonstrated the significant role of autonomous regulation for affective state regulation with an ambulatory assessment approach and, therefore, testing the hypotheses of the SDT about autonomous regulation in ongoing real-life situations.

Regarding the interaction of aPA and autonomous regulation mode on affective states, we showed that the higher the volume of aPA, and thereby the more autonomously regulated, the preceding bout of aPA was, the more our participants reported feeling energized (energetic arousal) and agitated (calmness [-]). We did not detect this interaction for valence (i.e., feeling well). To the best of our knowledge, no former study has depicted this interaction as an acute effect on momentary affective state. The findings underline the idea that the impact of aPA on affective states is moderated in situ by the degree to which such aPA episodes are autonomously regulated. This is an interesting finding, which we think could trigger theoretical modeling of the association between aPA and affective states.

A number of limitations to our research warrant discussion. First, undoubtedly, even the shortest ambulant assessments of data will interrupt the "natural" flow of ongoing behaviors, and therefore trigger some kind of reconstructive deliberation. But, because at present we have no other choice than to rely on self-report data to assess complex motivational states, true online measurements without interruptions are impossible. So, from a methodological viewpoint, using ambulant assessments is the state-of-the-art method to get intuitive descriptions about what's going on in peoples' minds during real-life situations. Second, only university students have been assessed, which resulted in a population sample that is both younger and of a higher socioeconomic status than the overall population. Third, because we have worked with a small sample size, we were not able to include time-invariant predictors (e.g., trait-level individual difference measures) on Level 2. Nevertheless, there are several studies indicating that subjective well-being is affected by personality, context, or gender differences (Diener, Suh, Lucas, \& Smith, 1999). For instance, future studies should also analyze variations of Level-1 intercepts (affective states) and Level-1 slopes (aPA, autonomous regulation, the interaction) as a function of sex, personality, or overall affects. Further studies can also explore how situational autonomous regulation connects with an individual's grade of satisfaction 
concerning his or her overall psychological need for autonomy. Fourth, aPA and all psychological variables were assessed in the course of only 1 day. Even though our postassessment interview did not suggest tremendous biases, we do not know whether the monitored day was a "normal" day for our participants with respect to their aPA and affective state. Further studies could enlarge the assessment period to more than 1 day. Lastly, the averaged intensity of our physical activity episodes just before the e-diary prompts was quite low. Although the range of our accelerometry data proves that we have caught some situations with high aPA, most of the captured episodes displayed notably low aPA. Further research should assess affective states during different aPA intensities to achieve a more balanced distribution of more active or less active behavioral episodes.

Our results allow for preliminary implications. The significant interactions underline the notion that the impact of aPA in everyday life on affective states is moderated by the degree to which such activity episodes are regulated autonomously and that they may be much more of an instant feeling than a deliberate cognitive reconstruction of what happened hours ago. In sum, this means that a person could achieve physiological effects if he or she follows the advice from an activity intervention. But he or she may feel even better the more the recommended activity has been integrated into his or her own value system. Exercise psychologists (or therapists, depending on the setting) might help subjects toward achieving this.

\section{References}

Diener, E., Suh, E.M., Lucas, R.E., \& Smith, H.L. (1999). Subjective well-being: Three decades of progress. Psychological Bulletin, 125, 276-302.

Duncan, L.R., Hall, C.R., Wilson, P.M., \& Jenny, O. (2010). Exercise motivation: A crosssectional analysis examining its relationships with frequency, intensity, and duration of exercise. The International Journal of Behavioral Nutrition and Physical Activity, 7, 7.

Ebner-Priemer, U.W., \& Trull, T.J. (2009). Ecological momentary assessment of mood disorders and mood dysregulation. Psychological Assessment, 21(4), 463-475.

Fahrenberg, J., Myrtek, M., Pawlik, K., \& Perrez, M. (2007). Ambulatory assessment: Monitoring behavior in daily life settings. European Journal of Psychological Assessment, 23, 206-213.

Kanning, M., \& Schlicht, W. (2010). Be active and become happy: An ecological momentary assessment of physical activity and mood. Journal of Sport \& Exercise Psychology, $32,253-261$.

Myrtek, M. (2004). Heart and emotion: Ambulatory monitoring studies in everyday life. Göttingen: Hogrefe.

Prince, S.A., Adamo, K.B., Hamel, M.E., Hardt, J., Gorber, S.C., \& Tremblay, M. (2008). A comparison of direct versus self-report measures for assessing physical activity in adults: a systematic review. The International Journal of Behavioral Nutrition and Physical Activity, 5, 56.

Puetz, T.W., O'Connor, P.J., \& Dishman, R.K. (2006). Effects of chronic exercise on feelings of energy and fatigue: a quantitative synthesis. Psychological Bulletin, 132, 866-876.

Raudenbush, S.W., Bryk, A., \& Congdon, R. (2004). HLM6: SSI Scientific Software International. Retrieved from www.ssicentral.com.

Reed, J., \& Ones, D.S. (2006). The effect of acute aerobic exercise on positive activated affect: A meta-analysis. Psychology of Sport and Exercise, 7, 477-514. 
Reis, H.T., Sheldon, K.M., Gable, S.L., Roscoe, J., \& Ryan, R.M. (2000). Daily well-being: The role of autonomy, competence, and relatedness. Personality and Social Psychology Bulletin, 26, 419-435.

Ryan, R.M., \& Deci, E.L. (2000). Self-determination theory and the facilitation of intrinsic motivation, social development, and well-being. The American Psychologist, 55, 68-78.

Sebire, S.J., Standage, M., \& Vansteenkiste, M. (2011). Predicting objectively assessed physical activity from the content and regulation of exercise goals: evidence for a meditational model. Journal of Sport \& Exercise Psychology, 33(2), 175-197.

Sheldon, K.M., \& Elliot, A.J. (1999). Goal striving, need satisfaction, and longitudinal well-being: The self-concordance model. Journal of Personality and Social Psychology, 76, 482-497.

Smith, A.L, Ntoumanis, N., Duda, J.L., \& Vansteenkiste, M. (2011). Goal striving, coping, and well-being: A prospective investigation of the self-concordance model in sport. Journal of Sport \& Exercise Psychology, 33, 124-145.

Snijders, T.A.B., \& Bosker, R. (2011). Multilevel analysis: An introduction to basic and advanced multilevel modeling. London: Sage Publications.

Steyer, R., Schwenkmezger, P., Notz, P., \& Eid, M. (1997). Der Mehrdimensionale Befindlichekeitsfragebogen $(M D B F)$. Göttingen: Hogrefe.

Taylor, I.M., Ntoumanis, N., Standage, M., \& Spray, C.M. (2010). Motivational predictors of physical education students' effort, exercise intentions, and leisure-time physical activity: A multilevel linear growth analysis. Journal of Sport \& Exercise Psychology, 32, 99-120.

Wilson, P.M., Rodgers, W.M., Fraser, S.N., \& Murray, T.C. (2004). Relationships between exercise regulations and motivational consequences in university students. Research Quarterly for Exercise and Sport, 75(1), 81-91.

Wilson, P.M., Blanchard, C.M., Nehl, E., \& Baker, F. (2006). Predicting physical activity and outcome expectations in cancer survivors: An application of self-determination theory. Psycho-Oncology, 15(7), 567-578.

Wilhelm, P., \& Schoebi, D. (2007). Assessing mood in daily life: Structural validity, sensitivity to change, and reliability of a short-scale to measure three basic dimensions of mood. European Journal of Psychological Assessment, 23, 258-267. 